Pesq. Vet. Bras. 38(4):703-709, abril 2018

\title{
Dantrolene e células-tronco mesenquimais promovem melhora funcional em ratos Wistar com trauma espinhal agudo ${ }^{1}$
}

\author{
Bruno B.J. Torres ${ }^{2 *}$, Bernardo C. Martins ${ }^{3}$, Carla Maria O. Silva ${ }^{2}$, \\ Mário Sérgio L. Lavor ${ }^{4}$, Sandro Coelho ${ }^{2}$, Gabriela F. Siano ${ }^{2}$ e Eliane G. Melo²
}

\begin{abstract}
Torres B.B.J., Martins B.C., Silva C.M.O., Lavor M.S.L., Coelho S., Siano G.F. \& Melo E.G. 2018. [Dantrolene and mesenchymal stem cells promote functional improvement in Wistar rats with spinal cord injury.] Dantrolene e células-tronco mesenquimais promovem melhora funcional em ratos Wistar com trauma espinhal agudo. Pesquisa Veterinária Brasileira 38(4):703-709. Unidade Acadêmica de Garanhuns, Universidade Federal Rural de Pernambuco, Avenida Bom Pastor s/n, Boa Vista, Garanhuns, PE 55292-270, Brazil. E-mail: brunobjtorres@yahoo.com.br

This study aimed to evaluate the effects of dantrolene (DAN) and mesenchymal stem cells (MSCs) in acute spinal cord injury (SCI). Sixty Wistar rats were divided into groups MSCs, MSCs + DAN, DAN, trauma and placebo (TP) and no trauma and placebo (STP). Laminectomy was performed at T12 level in all animals, followed by a weight-drop model of SCI, except for the STP group. An hour later, the MSCs + DAN and DAN groups received $10 \mathrm{mg} / \mathrm{kg}$ of DAN. After seven days, the MSCs and MSCs + DAN groups received $1 \times 10^{6}$ cells intravenously. Behavioral tests were performed to assess functional recovery for 28 days. Traumatized animals showed paraplegia. There was a significant improvement in groups MSCs, DAN and MSCs + DAN compared to TP $(p<0.05)$. It was concluded that DAN and MSCs for the treatment of $\mathrm{SCI}$ in rats have neuroprotection effect and promote functional neurological improvement.
\end{abstract}

INDEX TERMS: Dantrolene, mesenchymal stem cells, functional improvement, Wistar rats, spinal cord injury, cellular therapy, calcium channel blockers, behavior rating scale, rats.

RESUMO-- Objetivou-se avaliar o efeito do dantrolene (DAN) e das células-tronco mesenquimais (CTM) no trauma espinhal agudo (TEA). Sessenta ratos Wistar foram divididos nos grupos CTM, DAN + CTM, DAN, trauma e placebo (TP) e sem trauma e placebo (STP). Realizou-se laminectomia de T12 em todos os grupos, seguida de TEA contusivo/compressivo, com exceção do grupo STP. Uma hora depois, os grupos DAN + CTM e DAN receberam $10 \mathrm{mg} / \mathrm{kg}$ de DAN. Após sete dias os grupos CTM e DAN + CTM receberam $1 \times 10^{6}$ células, por via

\footnotetext{
${ }^{1}$ Recebido em 8 de abril de 2017.

Aceito para publicação em 21 de agosto de 2017.

${ }^{2}$ Escola de Veterinária e Zootecnia, Universidade Federal de Goiás (EVZ/UFG). Campus Samambaia, Avnida Esperança, s/n, Campus Universitário, Goiânia-GO, 74690-900, Brasil.*Autor para correspondência: brunobjtorres@yahoo.com.br

${ }^{3}$ Escola de Veterinária, Universidade Federal de Minas Gerais (UFMG). Av. Antônio Carlos 6627, Caixa Postal 567, campus Pampulha, Belo Horizonte, MG 31270-901, Brasil. E-mails: bernardodcmartins@hotmail.com, carlaosorio@yahoo.com.br, sandrocoelho13@yahoo.com.br, g_siano@hotmail.com, eliane@vet.ufmg.br

${ }^{4}$ Universidade Estadual de Santa Cruz, Campus Soane Nazaré de Andrade, Rodovia Jorge Amado Km 16, Bairro Salobrinho, Ilhéus, BA 45662-900, Brasil. E-mail: mariolavor@gmail.com
}

intravenosa. Testes comportamentais foram realizados para avaliar a recuperação funcional durante 28 dias. Os animais traumatizados apresentaram paraplegia. Houve melhora funcional significativa nos grupos tratados com CTM, DAN ou associação DAN + CTM em comparação ao grupo TP $(\mathrm{p}<0,05)$. Conclui-se que o DAN e as CTM para tratamento de TEA em ratos apresentam efeitos neuroprotetores e promovem melhora neurológica funcional.

TERMOS DE INDEXAÇÃO: Dantrolene, células-tronco mesenquimais, recuperação funcional, ratos Wistar, trauma espinhal agudo, traumatismos da medula espinal, terapia celular, bloqueadores dos canais de cálcio, escala de avaliação comportamental, ratos.

\section{INTRODUÇÃO}

O trauma espinhal produz dano primário no local do impacto, seguido por lesão secundária tardia que se estende craniocaudalmente, levando à degeneração progressiva do tecido neural. A neurodegeneração é caracterizada pela perda de neurônios e células gliais e, consequentemente, gera déficits funcionais motores, sensoriais e autonômicos. A lesão 
secundária é desencadeada por uma série complexa de eventos celulares que induz a morte por apoptose dentro de poucas horas a vários dias após o trauma inicial (Crowe et al. 1997, Springer et al. 1999, Han et al. 2015, Yousefifard et al. 2016).

Dentre os vários estímulos que promovem ativação dos fatores apoptóticos está a sobrecarga do íon cálcio $\left(\mathrm{Ca}^{2+}\right)$ no meio intracelular (Springer et al. 1999, Oo et al. 2015). Estudos demonstram que a liberação de $\mathrm{Ca}^{2+}$ das reservas intracelulares, como retículo endoplasmático, leva ao seu acúmulo citoplasmático que, por sua vez, sinaliza os neurônios para apoptose (Springer et al. 1999, Kobayashi et al. 2005, Oo et al. 2015).

A reversão desses eventos constitui uma das principais metas no tratamento de pacientes com lesão espinhal (Crowe et al. 1997, Dasari et al. 2007). Entretanto, devido à complexidade das inter-relações entre os diferentes mecanismos moleculares que participam das lesões secundárias, é improvável que uma única linha terapêutica promova retorno funcional completo.

0 papel da maioria das terapias na fase aguda pós-traumática deve ser preservar os axônios e maximizar suas funções, ao mesmo tempo em que se objetiva limitar a subsequente perda neuronal e glial (Coutts \& Keirstead 2008, Han et al. 2015). Posteriormente, intervenções que visam a regeneração funcional de axônios lesionados e restauração de conexões supra espinhais interrompidas, são essenciais para a recuperação funcional do paciente (McCall et al. 2012). A real necessidade de terapias combinadas vem sendo amplamente aceita, e agentes que possam atuar em diferentes vias de sinalização envolvidas diretamente na lesão secundária são de particular interesse.

O dantrolene, um inibidor da liberação de reservas intracelulares $\mathrm{de}^{2}{ }^{2+}$, pelo bloqueio de receptores rianodina presentes no retículo endoplasmático, surge como uma opção terapêutica promitente (Kobayashi et al. 2005, Oo et al. 2015). Seus efeitos neuroprotetores em modelos de trauma espinhal ex vivo, in vivo e in vitro já foram demonstrados (Thorell et al. 2002, Kocogullari et al. 2008, Aslan et al. 2009). Recentemente, nosso grupo de pesquisa demonstrou, pela primeira vez, o potencial efeito neuroprotetor do dantrolene por inibição de apoptose neuronal em modelo in vivo de trauma espinhal agudo (TEA) (Torres et al. 2010a).

Adicionalmente, o uso de terapia celular é uma estratégia promissora para o tratamento de doenças neurodegenerativas, seja via ação direta, por meio de sua diferenciação em neurônios que irão substituir aqueles que foram lesionados (Woodbury et al. 2000, Rooney et al. 2009), seja via supressão de inflamação local, ou pela estimulação da produção de citocinas, quimiocinas e fatores de crescimento (Himes et al. 2006, Dasari et al. 2007, Sasaki et al. 2009, Osaka et al. 2010, Oliveri et al. 2014), os quais, supostamente, favorecem a neurogênese das células-tronco (CT) neurais endógenas e o reparo tecidual (Jaerve et al. 2012, Yousefifard et al. 2016).

Entretanto, a baixa viabilidade das células após transplante para uma área lesada, obviamente restringe a eficácia dessa promissora terapia (Oliveri et al. 2014, Zhang \& He 2014). Imediatamente após o trauma, as CT transplantadas se deparam com um microambiente isquêmico, com pouca oferta de nutrientes essenciais e oxigênio para um metabolismo adequado, o que diminui sua sobrevivência e limita seus efeitos neuroprotetores (Jaerve et al. 2012, Han et al. 2015).
Espera-se que a utilização de um fármaco neuroprotetor, como o dantrolene, diminua a apoptose e preserve o tecido neural após a indução do TEA. Isso resultaria em um microambiente mais propício para a sobrevivência das CT transplantadas, determinando em melhoria da ação reparadora promovida por elas e, consequentemente, em recuperação funcional neurológica.

Portanto, objetivou-se avaliar a recuperação funcional neurológica de ratos Wistar submetidos ao trauma grave da medula espinhal e tratados com dantrolene, CTM ou associação de ambos, por meio de testes comportamentais durante 28 dias.

\section{MATERIAL E MÉTODOS}

O estudo foi aprovado pelo Comitê de Ética no Uso de Animais da UFMG, e recebeu protocolo de número 46/2012. Utilizaram-se 60 machos adultos da espécie Rattus norvegicus, variedade Wistar, com 20 semanas de idade e peso médio de $450 \mathrm{~g}$, mantidos em ambiente com temperatura controlada em ciclos de claro-escuro de 12 horas, e com ração comercial para roedores e água ad libitum. Os ratos Wistar foram distribuíd os aleatoriamente em cinco grupos experimentais com 12 animais cada (Quadro 1).

As CTM indiferenciadas foram isoladas das tíbias e fêmures de cinco ratos Wistar de oito semanas de idade. Foram isoladas e expandidas como descrito anteriormente (Song et al. 2014), e cultivadas em meio Eagle Modificado por Dulbecco (DMEM) suplementado com $10 \%$ de soro fetal bovino. 0 meio de cultura foi trocado uma vez a cada três dias, e as células não aderidas eram descartadas. A identidade das CTM indiferenciadas foi confirmada por sua propriedade de aderência ao plástico, morfologia celular e expressão específica dos antígenos de superfície. A caracterização morfológica das CTM foi observada em microscópio de contraste de fase invertida (IX70, Olympus, Tóquio, Japão). As CTM foram tripsinizadas e coradas com anticorpos CD45, CD54 e CD90 (BD Pharmingen, Franklin Lakes, NJ, EUA) marcados com fluoresceína para análise de citometria de fluxo.

Os ratos Wistar receberam medicação pré-anestésica a base de tramadol ( $2 \mathrm{mg} / \mathrm{kg}$, via oral) seguida de indução e manutenção anestésicas com isoflurano por máscara em sistema semiaberto. Os animais foram posicionados em decúbito esternal, preparados para cirurgia asséptica e receberam antibioticoterapia profilática a base de cefalexina (30mg/kg, intravenoso) conforme Torres et al. (2010b). Foi realizada cirurgia de laminectomia de T12, para exposição da medula espinhal íntegra envolta pelas meninges. Em seguida, produziu-se o TEA, exceto no grupo STP. Para isso, empregou-se o aparelho estereotáxico desenvolvido na EV-UFMG para contusão

Quadro 1. Grupos experimentais

\begin{tabular}{cccccc}
\hline Identificação & N & Laminectomia & TEA & 1 hora após & 7 dias após \\
\hline CTM & 12 & Sim & Sim & Placebo & CTM \\
CTM + DAN & 12 & Sim & Sim & DAN & CTM \\
DAN & 12 & Sim & Sim & DAN & Placebo \\
TP & 12 & Sim & Sim & Placebo & Placebo \\
STP & 12 & Sim & Não & Placebo & Placebo
\end{tabular}

CTM = células-tronco mesenquimais, DAN = dantrolene, $\mathrm{TP}=$ trauma $\mathrm{e}$ placebo, STP = sem trauma e placebo, $\mathrm{N}$ = número de animais por grupo, TEA = trauma espinhal agudo. 
com peso de $70 \mathrm{~g}$ que permaneceu por cinco minutos comprimindo a medula espinhal exposta (Torres et al. 2010b).

Uma hora após a laminectomia, os animais foram tratados com $10 \mathrm{mg} / \mathrm{kg}$ de dantrolene (Dantrolen IV ${ }^{\circledR}$. Cristália Produtos Químicos Farmacêuticos Ltda. Itapira, SP, Brasil) ou volume equivalente de seu placebo (água estéril para injeção), ambos pela via intraperitoneal, conforme Torres et al. (2010a). Sete dias após a cirurgia, os animais foram tratados com $200 \mu \mathrm{L}$ de PBS contendo $1 \times 10^{6}$ de CTM ou volume equivalente de seu placebo ( $200 \mu \mathrm{L}$ de PBS), aplicados pela veia lateral da cauda.

Os testes comportamentais foram realizados para avaliar a função neurológica dos animais, e basearam-se no método de escala descritiva adaptada (MEDA) já descrito anteriormente (Silva et al. 2008, Torres et al. 2010b) e consistiu na observação da capacidade motora (CM) e dos posicionamentos proprioceptivo (PP) e tátil (PT), bem como da permanência em estação no plano inclinado (PI), e da avaliação da sensibilidade dolorosa (SD). Todas as avaliações foram realizadas 24 horas antes do procedimento cirúrgico e, no período pós-operatório, foram realizadas em 24 horas e a cada três dias até o $28^{\circ}$ dia $\left(0,1^{\circ}, 4^{\circ}, 7^{\circ}, 10^{\circ}, 13^{\circ}, 16^{\circ}, 19^{\circ}, 22^{\circ}, 25^{\circ}, 28^{\circ}\right)$.

Os escores foram submetidos à análise de variância pelo teste de two-way e a significância entre as médias estabelecidas pelos testes de Bonferroni, adotando como nível de significância 5\%.

\section{RESULTADOS E DISCUSSÃO}

As CTM alógenas obtidas da medula óssea cresceram em monocamada de células grandes, planas e com baixa densidade de plaqueamento. À medida que as células se aproximavam da confluência, assumiam morfologia fibroblástica, fusiforme
(Fig.1). Utilizando a análise de citometria de fluxo, as CTM indiferenciadas de ratos demonstraram marcação negativa para $\mathrm{CD} 45(<2,45 \%)$, um marcador de superfície associado às células linfo-hematopoiéticas (Ishii et al. 2005). Usando análise de citometria de fluxo e imunocitoquímica, as células foram positivas para CD54 e CD90 (82,27\% e 87,89\%, respectivamente) (Fig.2), que são relatados como marcadores de superfície de células-tronco mesenquimais (Dominici et al. 2006).

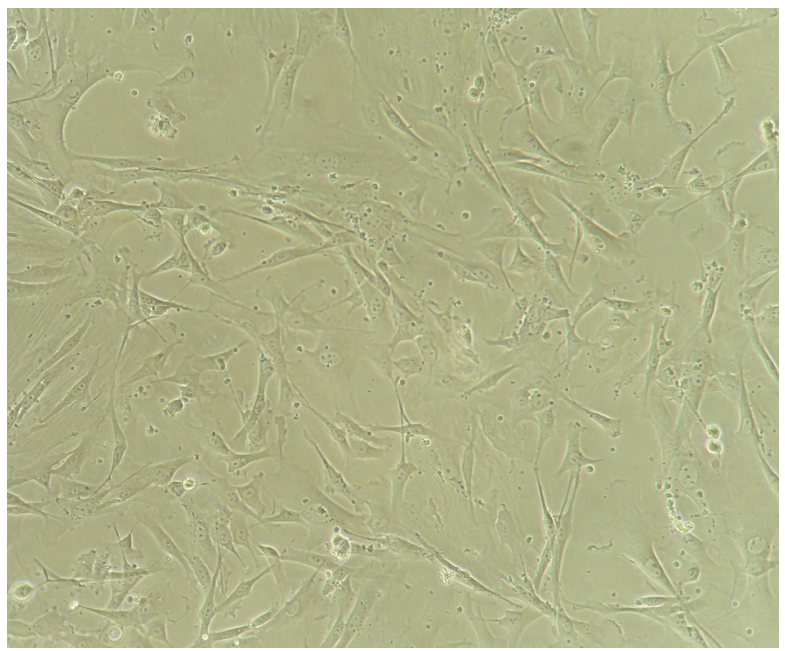

Fig.1. Células-tronco mesenquimais indiferenciadas da medula óssea de ratos, cultivadas em garrafa $T 75 \mathrm{~cm}^{2}$ contendo DMEM e $10 \%$ de soro fetal bovino, vista em microscópio invertido. $100 \mu \mathrm{m}$.
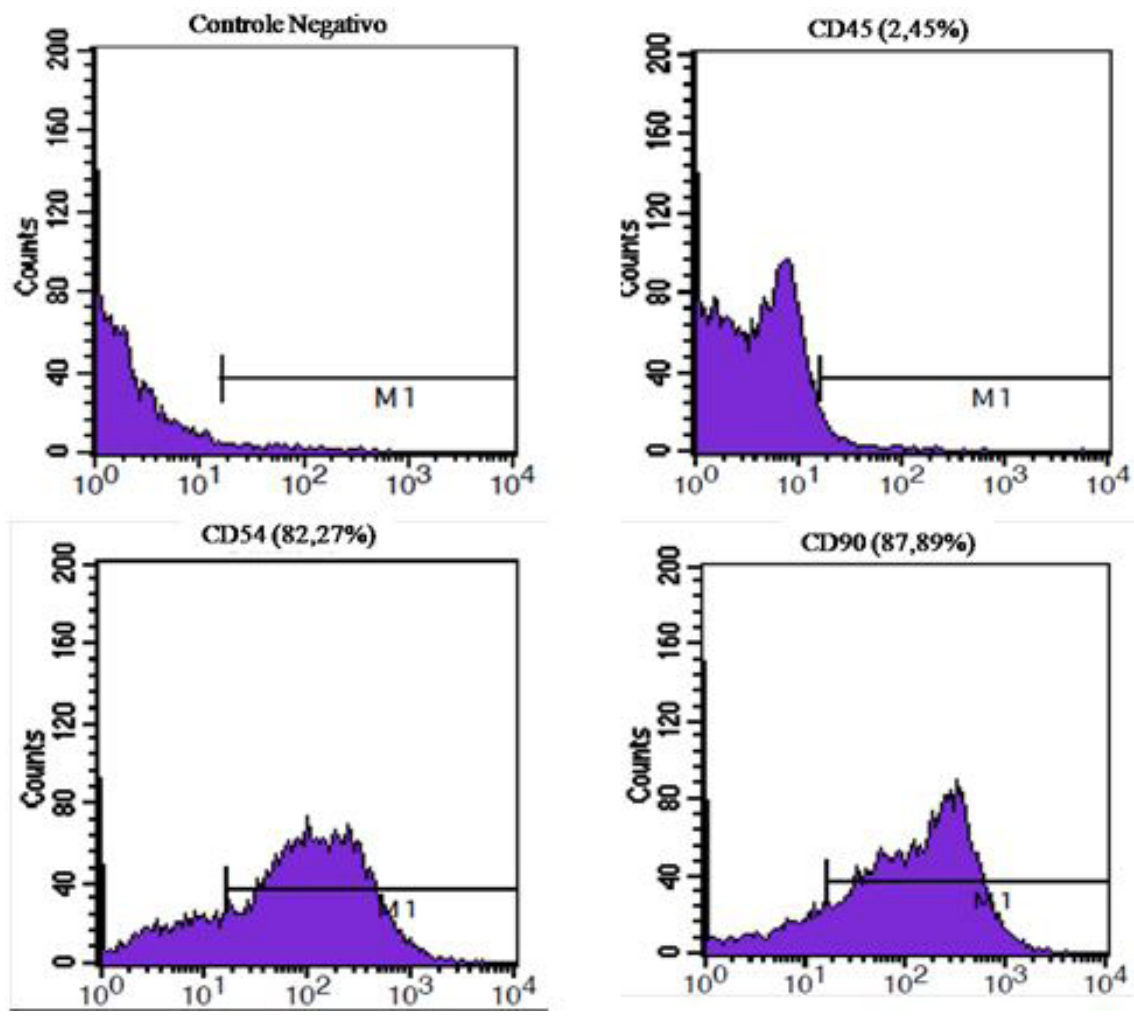

Fig.2. Histogramas da citometria de fluxo com o padrão de expressão das moléculas de superfície presentes em CTM indiferenciadas da medula óssea de ratos após oitava passagem. Estas células apresentaram imunomarcação de 2,45\% para o antígeno CD45, 82,27\% para o CD54 e 87,89\% para o CD90. M1 = imunomarcação positiva das células acima de 101. 
Após os procedimentos cirúrgicos, os animais do grupo STP permaneceram capazes de caminhar sobre a barra de $1,7 \mathrm{~cm}$ e também não apresentaram nenhum déficit neurológico nos demais testes. Esses resultados estão de acordo com os de Silva et al. (2008) e Torres et al. (2010b) que não observaram déficits nos ratos submetidos somente à laminectomia.

Todos os animais dos demais grupos experimentais que foram submetidos ao TEA (CTM, CTM+DAN, DAN e TP) apresentaram déficit neurológico grave na primeira avaliação que ocorreu 24 horas após o procedimento cirúrgico. No teste de CM (Fig.3) observou-se paraplegia dos membros pélvicos e, portanto, incapacidade de apoio do peso sobre os mesmos. Ausência de resposta nos testes de SD (Fig.4), PP (Fig.5) e PT (Fig.6) também foi observada, e os animais não foram capazes de se manter em angulação superior a $60^{\circ}$ no PI (Fig.7). Resultados semelhantes foram descritos por Silva et al. (2008).

Nenhum dos animais traumatizados apresentou recuperação total das funções após 28 dias de avaliação. Em todos os grupos, exceto o TP, os ratos recuperaram progressivamente diferentes graus de função sensorial e motora ao longo do período de avaliação, o que foi observado com maior intensidade nos grupos tratados com CTM, dantrolene ou associação de ambos.

A partir do 4음 dia os animais do grupo DAN apresentavam SD (Fig.4) significativamente maior que os do grupo TP $(p<0,001)$, e a partir do $13^{\circ}$ dia apresentaram recuperação semelhante aos animais normais do grupo STP $(p>0,05)$. Aos 7 dias, os animais do grupo DAN apresentavam maior SD que os animais do grupo CTM $(p<0,001)$ e CTM+DAN $(p<0,01)$. A partir do 7o dia os animais do grupo CTM+DAN apresentavam SD significativamente maior que os do grupo TP $(p<0,01)$, e partir do 16을 dia apresentaram SD semelhante aos dos animais não traumatizados do grupo STP $(p>0,05)$. No $10^{\circ}, 13^{\circ}$ e a partir do $25^{\circ}$ dia, os animais do grupo CTM apresentavam SD significativamente maior que os do grupo TP $(p<0,001)$, e a partir do 25을 dia apresentaram SD semelhante à dos animais não traumatizados do grupo STP $(p>0,05)$. Os animais do grupo TP não apresentaram recuperação da SD em relação aos animais do grupo STP $(p<0,001)$ em nenhum momento durante o período de observação.

No teste de CM (Fig.3), no $13^{\circ}(\mathrm{p}<0,05)$ e a partir do 19 o $(p<0,001)$ dia, os animais do grupo CTM apresentavam apoio de peso nos membros pélvicos com déficit acentuado, resultado significativamente maior que os do grupo TP, cujos animais continuavam sem nenhuma movimentação nem apoio de peso. A partir do 16음 dia os animais do grupo CTM+DAN apresentavam movimento bem visível nos membros pélvicos, sem apoio de peso, resultado significativamente maior que os do grupo TP $(\mathrm{p}<0,05)$. A partir do $22^{\circ}$ dia os animais do grupo DAN apresentavam movimento bem visível nos membros pélvicos, sem apoio de peso, resultado significativamente maior que os do grupo TP $(\mathrm{p}<0,05)$. Os animais do grupo TP não apresentaram recuperação da CM em relação aos animais não traumatizados do grupo STP $(p<0,001)$.

De forma semelhante, nos testes de PP (Fig.5) e PT (Fig.6), somente os animais do grupo CTM apresentavam melhora a partir do $22^{\circ}$ dia em relação aos do grupo TP $(p<0,01)$. Os animais do grupo CTM+DAN, DAN e TP não apresentaram recuperação de PP e PT em relação aos animais não traumatizados do grupo STP $(\mathrm{p}<0,001)$.

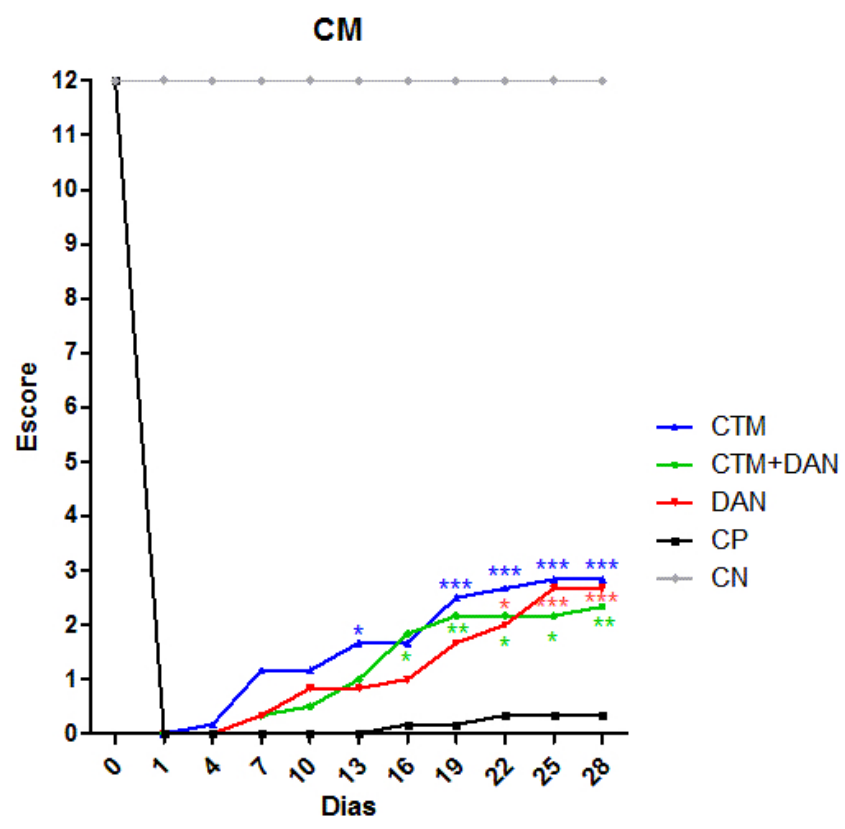

Fig.3. Gráfico mostrando a evolução dos escores (média) do teste de Capacidade Motora (CM), segundo o método de escala descritiva adaptada entre os grupos, durante 28 dias de avaliação de ratos Wistar, submetidos a trauma espinhal agudo e tratados com células-tronco mesenquimais (CTM), células-tronco mesenquimais associadas ao dantrolene (CTM + DAN), dantrolene (DAN) ou placebo (trauma e placebo - TP). Os animais do grupo sem trauma e placebo (STP) foram submetidos apenas à laminectomia sem trauma espinhal e foram tratados com placebo. ${ }^{*} \mathrm{p}<0,05 ;{ }^{* *} \mathrm{p}<0,01 ; \mathrm{p}<0,001$.

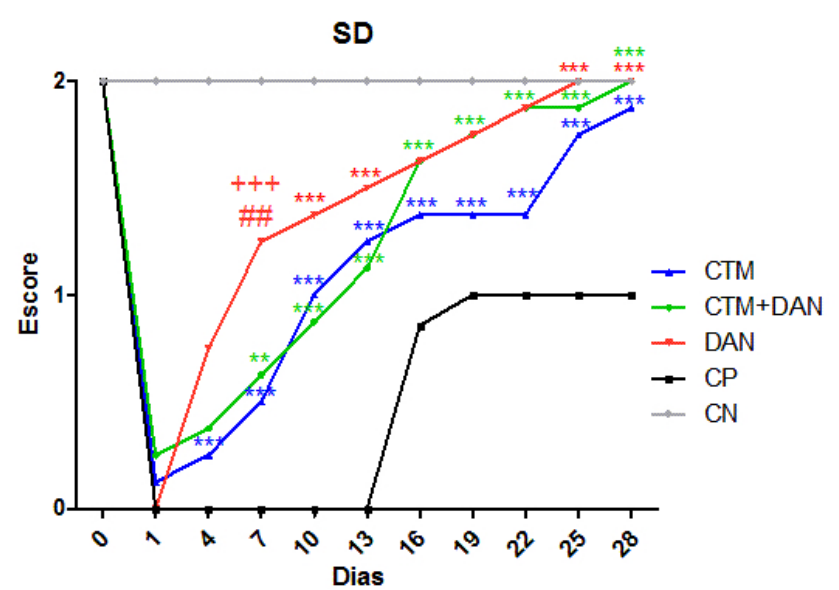

Fig.4. Gráfico mostrando a evolução dos escores (média) do teste de Sensibilidade Dolorosa (SD), segundo o método de escala descritiva adaptada entre os grupos, durante 28 dias de avaliação de ratos Wistar, submetidos a trauma espinhal agudo e tratados com células-tronco mesenquimais (CTM), células-tronco mesenquimais associadas ao dantrolene (CTM + DAN), dantrolene (DAN) ou placebo (trauma e placebo - TP). Os animais do grupo sem trauma e placebo o (STP) foram submetidos apenas à laminectomia sem trauma espinhal e foram tratados com placebo. ${ }^{*} \mathrm{p}<0,05 ;{ }^{* *} \mathrm{p}<0,01 ; \mathrm{p}<0,001$. 
No teste de PI (Fig.7), a partir do $22^{\circ}$ dia, os animais do grupo DAN apresentavam resultado significativamente maior que os do grupo TP $(\mathrm{p}<0,05)$. A partir do $25^{\circ}$ dia, os animais do grupo CTM apresentavam resultado significativamente maior que os do grupo TP $(\mathrm{p}<0,05)$. Os animais dos grupos

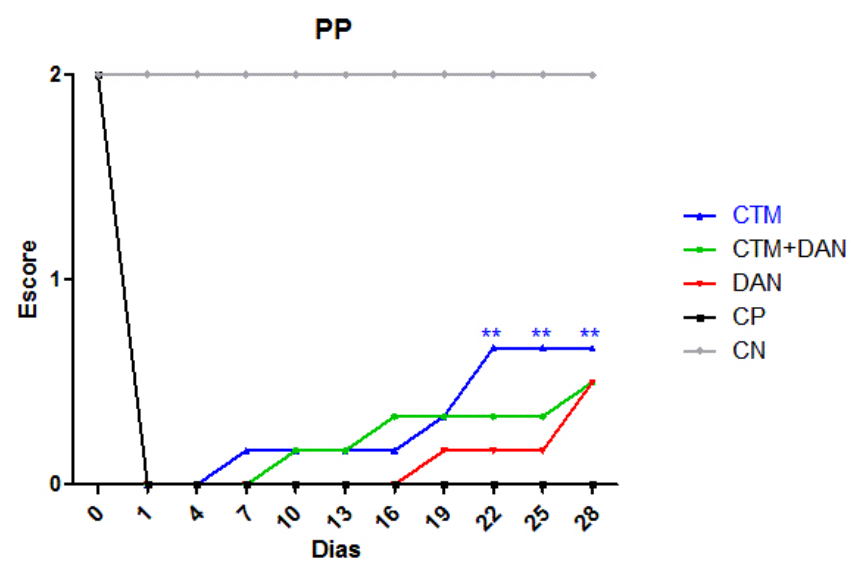

Fig.5. Gráfico mostrando a evolução dos escores (média) do teste de Posicionamento Proprioceptivo (PP), segundo o método de escala descritiva adaptada entre os grupos, durante 28 dias de avaliação de ratos Wistar, submetidos a trauma espinhal agudo e tratados com células-tronco mesenquimais (CTM), células-tronco mesenquimais associadas ao dantrolene (CTM + DAN), dantrolene (DAN) ou placebo (trauma e placebo - TP). Os animais do grupo sem trauma e placebo (STP) foram submetidos apenas à laminectomia sem trauma espinhal e foram tratados com placebo. ${ }^{*} \mathrm{p}<0,05 ;{ }^{* *} \mathrm{p}<0,01 ; \mathrm{p}<0,001$.

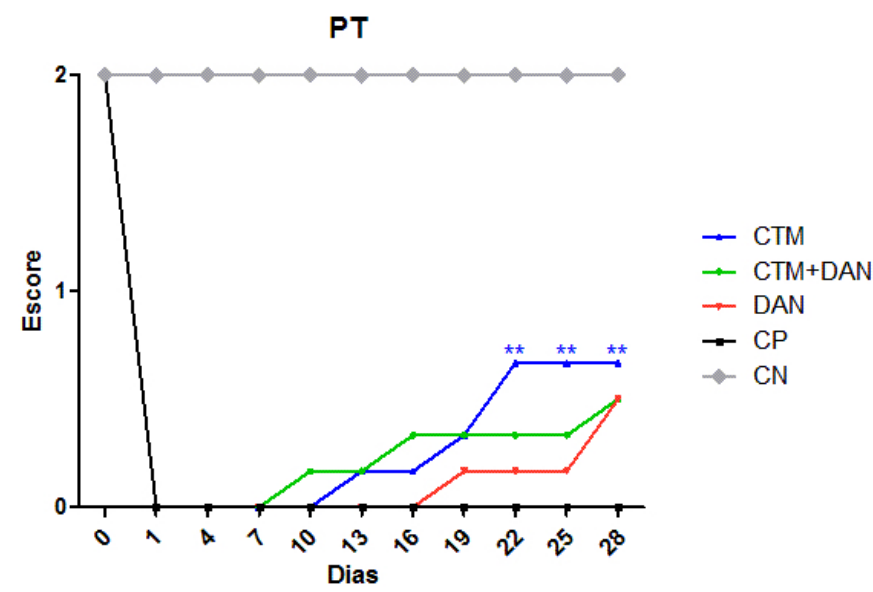

Fig.6. Gráfico mostrando a evolução dos escores (média) do teste de Posicionamento Tátil (PT), segundo o método de escala descritiva adaptada entre os grupos, durante 28 dias de avaliação de ratos Wistar, submetidos a trauma espinhal agudo e tratados com células-tronco mesenquimais (CTM), células-tronco mesenquimais associadas ao dantrolene (CTM + DAN), dantrolene (DAN) ou placebo (trauma e placebo - TP). Os animais do grupo sem trauma e placebo (STP) foram submetidos apenas à laminectomia sem trauma espinhal e foram tratados com placebo. ${ }^{*} \mathrm{p}<0,05 ;{ }^{* *} \mathrm{p}<0,01 ; \mathrm{p}<0,001$.
CTM+DAN e TP não apresentaram melhora no teste de PI em relação aos animais não traumatizados do grupo STP $(\mathrm{p}<0,001)$.

Optou-se pelo trauma grave nos animais estudados, uma vez que a recuperação espontânea e precoce após TEA discreto a moderado tem sido relatada, e pode dificultar a avaliação do tratamento proposto (Silva et al. 2008). Este evento pode ocorrer em função da adaptação ou do retorno funcional dos axônios temporariamente afuncionais que se mantiveram intactos em meio ao tecido danificado (Sasaki et al. 2009, McCall et al. 2012).

Existem poucos estudos que demonstram os efeitos do dantrolene sobre a recuperação funcional neurológica em TEA. Aslan et al. (2009) observaram melhora funcional significativa na avaliação pelo teste comportamental de Tarlov, em coelhos New Zeland tratados com $10 \mathrm{mg} / \mathrm{kg}$ de dantrolene em comparação aos animais não tratados, 24 horas após realização de trauma espinhal, pelo modelo de balão compressivo extradural. Entretanto, questiona-se se a recuperação funcional precoce relatada estaria realmente associada ao efeito neuroprotetor do fármaco, ou se seria recuperação espontânea, devido a um trauma compressivo discreto.

Em estudo anterior, não foi possível observar recuperação neurológica funcional em modelo experimental idêntico ao do presente estudo, cujos ratos foram tratados com $10 \mathrm{mg} / \mathrm{kg}$ de dantrolene e avaliados durante oito dias. Entretanto, esses animais apresentaram maior preservação neuronal (neurônios NeuN-positivos) e menor número de células apoptóticas (caspase-3-positivas), em comparação aos animais que receberam apenas placebo (Torres et al. 2010a). Por isso, aventou-se a necessidade de avaliação clínica por tempo prolongado para observar efeitos clinicamente positivos, devido à gravidade do trauma.

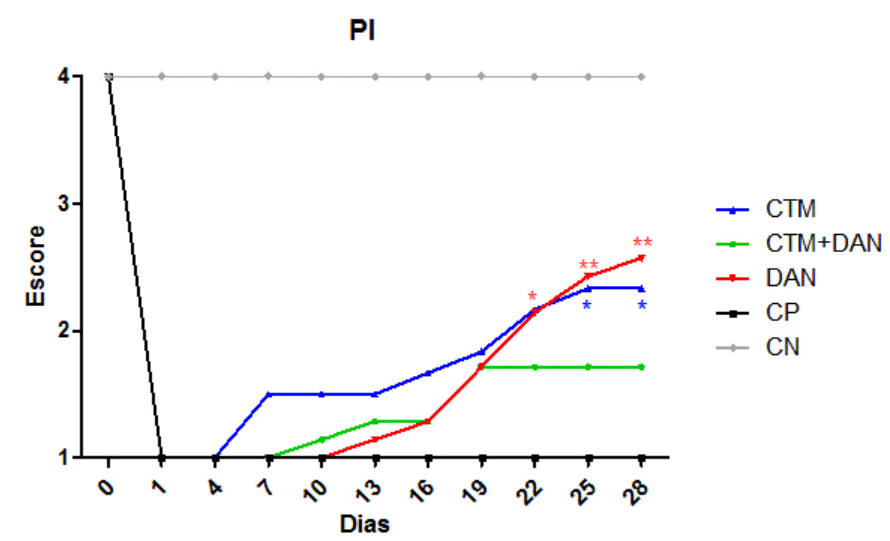

Fig.7. Gráfico mostrando a evolução dos escores (média) do teste de Plano Inclinado (PI), segundo o método de escala descritiva adaptada entre os grupos, durante 28 dias de avaliação de ratos Wistar, submetidos a trauma espinhal agudo e tratados com células-tronco mesenquimais (CTM), células-tronco mesenquimais associadas ao dantrolene (CTM + DAN), dantrolene (DAN) ou placebo (trauma e placebo - TP). Os animais do grupo sem trauma e placebo (STP) foram submetidos apenas à laminectomia sem trauma espinhal e foram tratados com placebo. ${ }^{*} \mathrm{p}<0,05 ;{ }^{* *} \mathrm{p}<0,01 ; \mathrm{p}<0,001$. 
Adicionalmente, diversos estudos demonstram a capacidade de recuperação neurológica funcional de ratos submetidos à TEA, após utilização de CT, via diferentes mecanismos de ação (Oliveri et al. 2014, Zhang \& He 2014, Yousefifard et al. 2016). Numerosos estudos têm sugerido que é mais provável que as CTM atuem por mecanismos parácrinos transitórios ao invés de sobreviverem por longo prazo e substituírem as células danificadas (Oliveri et al. 2014, Han et al. 2015). Além disso, é bem conhecido que, quando injetadas por via intravenosa, as CTM são capazes de migrar para o local da lesão e secretar fatores anti-inflamatórios, imunomoduladores, antiapoptóticos, tróficos e angiogênicos, desempenhando assim um papel neuroprotetor (Osaka et al. 2010, Jaerve et al. 2012, Zhang \& He 2014).

É interessante observar que nas avaliações da CM o grupo tratado com CTM apresentou retorno funcional precoce (22ํㅜ e $13^{\circ}$ dia, respectivamente) em relação aos demais grupos (CTM+DAN e DAN), quando comparados ao grupo que recebeu somente placebo (TP). Isso sugere um possível efeito neuroprotetor das CTM sobre as vias motoras corticoespinhais e rubroespinhais. Além disso, somente o grupo tratado com CTM demonstrou melhora da PP e PT, sugerindo possível efeito benéfico das células sobre os tratos sensitivos grácil e espinocerebelares. Em contrapartida, na avaliação de PI, somente o grupo DAN resultou em recuperação neurológica funcional, o que sugere ação desse fármaco sobre as vias sensoriais e motoras, avaliadas pelo teste. Finalmente, o grupo DAN apresentou melhores resultados sobre recuperação da SD, sugerindo seus efeitos benéficos sobre os tratos espinotalâmico e espinorreticular. Em contrapartida, ao contrário do que se esperava, a associação do DAN e CTM não demonstrou efeitos superiores que a utilização dessas terapias isoladas sobre a recuperação funcional dos ratos. Talvez o efeito significativo dessa associação possa ser observado com maior tempo de observação em estudos futuros.

O efeito das CT transplantadas e do dantrolene pode ter promovido melhor neuroplasticidade, seja por meio de preservação da integridade do tecido neural, fornecimento de estímulos tróficos ou inibição da apoptose, limitando, portanto, sua progressão para áreas adjacentes ao epicentro.

Além disso, a utilização das CTM em ratos submetidos à TEA tem demonstrado melhora funcional e diminuição de lesão secundária, tanto no transplante em sua forma indiferenciada, quanto geneticamente modificada para maior expressão das neurotrofinas (Sasaki et al. 2009, McCall et al. 2012).

Independente do mecanismo de ação das CTM indiferenciadas, seja por transdiferenciação (Woodbury et al. 2000, Dasari et al. 2007, Rooney et al. 2009), por preservação e/ou formação de novos circuitos via sinaptogênese, por carreamento de fatores neurotróficos ou estímulo de sua produção endógena (Himes et al. 2006, Osaka et al. 2010), parece consenso geral que a elevação das neurotrofinas apresenta papel relevante sobre tais melhoras dos pacientes traumatizados (Oliveri et al. 2014, Zhang \& He 2014, Han et al. 2015).

Por fim, embora a diferenciação neural das CTM implantadas não tenha sido objeto do atual estudo, sublinhar uma possível razão para a melhoria funcional sensorial e motora dos animais estudados é fundamental em estudos futuros. Além das funções diretas dessas terapias sobre o aumento dos fatores neurotróficos, especula-se que o uso do dantrolene e das CTM tenha proporcionado recuperação funcional, via preservação de células nervosas e, consequentemente, de maior função neuronal em longo prazo, que permitisse continuidade ao estímulo da produção e ação das neurotrofinas endógenas. A utilização inovadora do dantrolene e das CTM pode ser uma terapia promissora que deve ser estuda em mais detalhes, e pode ser uma opção potencial para aplicação em outras espécies com trauma espinhal agudo tanto em animais quanto, futuramente, em seres humanos.

\section{CONCLUSÕES}

O dantrolene e as CTM apresentam efeito neuroprotetor e promovem melhora funcional neurológica após TEA grave em ratos.

O uso da associação de ambos não é capaz de promover melhora funcional mais acentuada que aquela promovida pelos tratamentos isolados.

Agradecimentos.- À Cristália pela doação do dantrolene, ao CNPq pela bolsa de pesquisa e à FAPEMIG pelo financiamento do projeto.

\section{REFERÊNCIAS}

Aslan A., Cemek M., Büyükokuroglu M.E., Altunbas K., Bas O., Yurumez Y. \& Cosar M. 2009. Dantrolene can reduce secondary damage after spinal cord injury. Eur. Spine J. 18(10):1442-1451. http://dx.doi.org/10.1007/ s00586-009-1033-6. PMid:19468761.

Coutts M. \& Keirstead H.S. 2008. Stem cells for the treatment of spinal cord injury. Exp. Neurol. 209(2):368-377. http://dx.doi.org/10.1016/j. expneurol.2007.09.002. PMid:17950280.

Crowe M.J., Bresnahan J.C., Shuman S.L., Masters J.N. \& Crowe M.S. 1997. Apoptosis and delayed degeneration after spinal cord injury in rats and monkeys. Nat. Med. 3(1):73-76. http://dx.doi.org/10.1038/nm0197-73. PMid:8986744.

Dasari V.R., Spomar D.G., Cady C., Gujrati M., Rao J.S. \& Dinh D.H. 2007. Mesenchymal stem cells from rat bone marrow downregulate caspase-3mediated apoptotic pathway after spinal cord injury in rats. Neurochem. Res. 32(12):2080-2093. http://dx.doi.org/10.1007/s11064-007-9368-z. PMid:17564836.

Dominici M., Le Blanc K., Mueller I., Slaper-Cortenbach I., Marini F., Krause D., Deans R., Keating A., Prockop D.J. \& Horwitz E. 2006. Minimal criteria for defining multipotent mesenchymal stromal cells. The International Society for Cellular Therapy position statement. Cytotherapy 8(4):315317. http://dx.doi.org/10.1080/14653240600855905. PMid:16923606.

Han D., Wu C., Xiong Q., Zhou L. \& Tian Y. 2015. Anti-inflammatory mechanism of bone marrow mesenchymal stem cell transplantation in rat model of spinal cord injury. Cell Biochem. Biophys. 71(3):1341-1347. http://dx.doi. org/10.1007/s12013-014-0354-1. PMid:25388837.

Himes B.T., Neuhuber B., Coleman C., Kushner R., Swanger S.A., Kopen G.C., Wagner J., Shumsky J.S. \& Fischer I. 2006. Recovery of function following grafting of human bone marrow-derived stromal cells into the injured spinal cord. Neurorehabil. Neural Repair 20(2):278-296. http://dx.doi. org/10.1177/1545968306286976. PMid:16679505.

Ishii M., Koike C., Igarashi A., Yamanaka K., Pan H., Higashi Y., Kawaguchi H., Sugiyama M., Kamata N., Iwata T., Matsubara T., Nakamura K., Kurihara H., Tsuji K. \& Kato Y. 2005. Molecular markers distinguish bone marrow mesenchymal stem cells from fibroblasts. Biochem. Biophys. Res. Commun. 332(1):297-303.http://dx.doi.org/10.1016/j.bbrc.2005.04.118. PMid:15896330.

Jaerve A., Schira J. \& Müller H.W. 2012. Concise review: the potential of stromal cell-derived factor 1 and its receptors to promote stem cell functions in spinal cord repair. Stem Cells Transl. Med. 1(10):732-739. http://dx.doi. org/10.5966/sctm.2012-0068. PMid:23197665. 
Kobayashi S., Bannister M.L., Gangopadhyay J.P., Hamada T., Parness J. \& Ikemoto N. 2005. Dantrolene stabilizes domain interactions within the ryanodine receptor. J. Biol. Chem. 280(8):6580-6587. http://dx.doi. org/10.1074/jbc.M408375200. PMid:15611117.

Kocogullari C.U., Emmiler M., Cemek M., Sahin O., Aslan A., Ayva E., Tur L., Buyukokuroglu M.E., Demirkan I. \& Cekirdekci A. 2008. Can dantrolene protect spinal cord against ischemia/reperfusion injury? An experimental study. Thorac. Cardiovasc. Surg. 56(7):406-411. http:// dx.doi.org/10.1055/s-2008-1038731. PMid:18810698.

McCall J., Weidner N. \& Blesch A. 2012. Neurotrophic factors in combinatorial approaches for spinal cord regeneration. Cell Tissue Res. 349(1):27-37. http://dx.doi.org/10.1007/s00441-012-1388-6. PMid:22526621.

Oliveri R.S., Bello S. \& Biering-Sorensen F. 2014. Mesenchymal stem cells improve locomotor recovery in traumatic spinal cord injury: systematic review with meta-analyses of rat models. Neurobiol. Dis. 62:338-353. http://dx.doi.org/10.1016/j.nbd.2013.10.014. PMid:24148857.

Oo Y.W., Gomez-Hurtado N., Walweel K., Van Helden D.F., Imtiaz M.S., Knollmann B.C. \& Laver D.R. 2015. Essential role of calmodulin in RyR inhibition by dantrolene. Mol. Pharmacol. 88(1):57-63. http://dx.doi.org/10.1124/ mol.115.097691. PMid:25920678.

Osaka M., Honmou O., Murakami T., Nonaka T., Houkin K., Hamada H. \& Kocsis J.D. 2010. Intravenous administration of mesenchymal stem cells derived from bone marrow after contusive spinal cord injury improves functional outcome. Brain Res. 1343:226-235. http://dx.doi.org/10.1016/j. brainres.2010.05.011. PMid:20470759.

Rooney G.E., Howard L., O'brien T., Windebank A.J. \& Barry F.P. 2009. Elevation of cAMP in mesenchymal stem cells transiently upregulates neural markers rather than inducing neural differentiation. Stem Cells Development 18(3):387-398. http://dx.doi.org/10.1089/scd.2008.0080. PMid:18554089.

Sasaki M., Radtke C., Tan A.M., Zhao P., Hamada H., Houkin K., Honmou O. \& Kocsis J.D. 2009. BDNF-hypersecreting human mesenchymal stem cells promote functional recovery, axonal sprouting, and protection of corticospinal neurons after spinal cord injury. J. Neurosci. 29(47):14932-14941. http:// dx.doi.org/10.1523/JNEUROSCI.2769-09.2009. PMid:19940189.

Silva C.M.O., Melo E.G., Almeida A.E.R.F., Gomes M.G., Silva C.H.O., Rachid M.A., Verçosa Júnior D., Vieira N.T. \& França S.A. 2008. Efeito da prednisona em lesão medular aguda experimental em ratos. Arq. Bras. Med. Vet. Zootec. 60(3):641-650. http://dx.doi.org/10.1590/S0102-09352008000300018.

Song K., Huang M., Shi Q., Du T. \& Cao Y. 2014. Cultivation and identification of rat bone marrow-derived mesenchymal stem cells. Mol. Med. Rep. 10(2):755-760. http://dx.doi.org/10.3892/mmr.2014.2264. PMid:24859847.

Springer J.E., Azbill R.D. \& Knapp P.E. 1999. Activation of the caspase-3 apoptotic cascade in traumatic spinal cord injury. Nat. Med. 5(8):943-946. http://dx.doi.org/10.1038/11387. PMid:10426320.

Thorell W.E., Leibrock L.G. \& Agrawal S.K. 2002. Role of RYRs and IP3 receptors after traumatic injury to spinal cord white matter. J. Neurotrauma 19(3):335342. http://dx.doi.org/10.1089/089771502753594909. PMid:11939501.

Torres B.B., Caldeira F.M., Gomes M.G., Serakides R., Viott A.M., Bertagnolli A.C., Fukushima F.B., Oliveira K.M., Gomes M.V. \& Melo E.G. 2010a. Effects of dantrolene on apoptosis and immunohistochemical expression of NeuN in the spinal cord after traumatic injury in rats. Int. J. Exp. Pathol. 91(6):530-536. http://dx.doi.org/10.1111/j.1365-2613.2010.00738.x. PMid:21039984.

Torres B.B.J., Silva C.M.O., Almeida Á.E.R.F., Caldeira F.M.C., Gomes M.G., Alves E.G.L., Silva S.J. \& Melo E.G 2010b. Experimental model of acute spinal cord injury produced by modified steriotaxic equipment. Arq. Bras. Med. Vet. Zootec. 62(1):92-99. http://dx.doi.org/10.1590/S010209352010000100013.

Woodbury D., Schwarz E.J., Prockop D.J. \& Black I.B. 2000. Adult rat and human bone marrow stromal cells differentiate into neurons. J. Neurosci. Res. 61(4):364370. http://dx.doi.org/10.1002/1097-4547(20000815)61:4<364::AIDJNR2>3.0.CO;2-C. PMid:10931522.

Yousefifard M., Rahimi-Movaghar V., Nasirinezhad F., Baikpour M., Safari S., Saadat S., Moghadas Jafari A., Asady H., Razavi Tousi S.M. \& Hosseini M. 2016. Neural stem/progenitor cell transplantation for spinal cord injury treatment: a systematic review and meta-analysis. Neuroscience 322:377-397. http://dx.doi.org/10.1016/j.neuroscience.2016.02.034. PMid:26917272.

Zhang D. \& He X. 2014. A meta-analysis of the motion function through the therapy of spinal cord injury with intravenous transplantation of bone marrow mesenchymal stem cells in rats. PLoS One 9(4):e93487. http:// dx.doi.org/10.1371/journal.pone.0093487. PMid:24690752. 